\title{
Single- or multiple-session viscosupplementation protocols for temporomandibular joint degenerative disorders: a randomized clinical trial
}

\author{
L. GUARDA-NARDINI*, A.ROSSI*, R.ARBORETTI ${ }^{\dagger}$, S.BONNINI*, E. STELLINI ${ }^{\S}$ \\ \& D. MANFREDINI* *Department of Maxillofacial Surgery, Temporomandibular Disorders Clinic, University of Padova, \\ Padova, ${ }^{\dagger}$ Department of Land Use and AgriForestal Systems, University of Padova, Padova, ${ }^{\star}$ Department of Economics and Management, \\ University of Ferrara, Ferrara, and ${ }^{\S}$ School of Dentistry, University of Padova, Padova, Italy
}

SUMMARY The aim of the study was to compare the effectiveness of two single-session protocols, either adopting high- (protocol A) or medium-molecular weight hyaluronic acid (protocol B), with the reference five-session protocol of temporom andibular joint (TMJ) lavage plus viscosuppl ementation (protocol $\mathrm{C}$ ) in the management of chronic TMJ degenerative disorders. A randomized clinical trial (RCT) with ten participants per treatment group was designed, with multiple observation points, ending at 6 months after treatment. Pain levels on a 10-point VAS scale were selected as the primary outcome variable to rate treatment effectiveness, along with a number of secondary outcome parameters. Findings showed that Group C patients had the highest decrease in pain levels. Nonparametric permutation analyses revealed that the global effect of treatment was significantly different between the three protocols $(P=0.024)$. Pairwise comparisons showed that the differences of treatment effect between the two single-session interventions were negligible (global
$P$-value $=0.93)$. On the contrary, the five-session protocol was significantly superior to both singlesession protocols (global $P$-values ranging from 0.003 to 0.012 ). In conclusion, in a population of age-, sex-, and psychosocial aspects-matched study groups, the standard of reference five-session protocol proved to be superior at $\mathbf{6}$ months as far as the decrease in pain levels was concerned, whilst there were no differences between the two single-session interventions. The absence of differences in treatment effect as for some other secondary clinical outcome variables may suggest that there is further space for future investigations attempting to reduce the number of multiple interventions for TMJ viscosupplementation.

KEYWORDS: temporomandibular joint, hyaluronic acid, arthrocentesis, viscosupplementation, osteoarthrosis

Accepted for publication 31 January 2015

\section{Introduction}

Degenerative disorders of the temporomandibular joint (TMJ) are a frequent cause of oro-facial pain (1). Over the years, several approaches have been proposed to manage symptoms due to such disorders and to improve joint function (2); among those, viscosupplementation with hyaluronic acid (HA) injections has been gaining diffusion (3). Such strategy has been introduced within the clinics of TMJ disorders as a result of the progressive changes to the classical TMJ arthrocentesis $(4,5)$ as well as of the increasing knowledge about the potential application of hyaluronic acid to manage osteoarthritis (OA) of larger joints $(6,7)$.

The potential role of joint lubrication impairment as a risk factor for TMJ internal derangements and the 
subsequent inflammatory-degenerative disorders provides a background for TMJ viscosupplementation (8), which is supported by the clinical evidence of its effectiveness (9-13). Notwithstanding that, much information is yet to be defined as far as the most suitable protocols and indications at the individual level are concerned. Several clinical trials have been conducted by our research group with the aim to customise treatment based on the identification of patient- and treatment-related outcome predictors (14-19).

An issue to be further explored is the definition of the ideal number of viscosupplementation sessions that are needed to warrant positive effects over time. A previous randomized clinical trial showed that a cycle of five interventions providing joint lavage plus low-molecular weight hyaluronic acid injections should be considered the reference protocol (15). Such data should be re-appraised on the basis of the recently shown potential effectiveness of higher molecular weight hyaluronic acids (17). In particular, strategies aiming to reduce the number of treatment sessions could be useful in terms of an improved biological and financial cost-to-benefit ratio. Based on this premise, the present investigation compared the effectiveness of two single-session protocols, either adopting medium- or high-molecular weight hyaluronic acid, with the reference five-session protocol of TMJ lavage plus viscosupplementation.

\section{Materials and methods}

To address the research purpose, a randomized clinical trial (RCT) was designed by recruiting patients among the attendees of the TMD Clinic, Department of Maxillofacial Surgery, University of Padova, Padova, Italy.

The first step was the calculation of the needed sample size for the investigation. The assessment of average pain levels with jaw function on a 10-point VAS scale, with 0 being absence of pain and 10 being the worst pain ever experienced, was selected as the primary outcome variable to rate treatment effectiveness. Data from previous investigations with similar study populations were used to assume a mean baseline VAS value of $6 / 10 \pm 3 / 10$ in the main outcome variable, viz. pain levels with jaw function, and an expected decrease of 4 VAS points for patients undergoing the reference five-session protocol $(10,11)$. The minimal clinical important difference (MCID) to detect, in accordance with literature suggestions, was set at 2 VAS points (20), thus representing a 50\% difference with respect to the expected VAS improvement in the reference study group. Based on such data, a formula to calculate the needed sample size to detect the between-group MCID was applied (21). Ten participants per group were needed to detect about a $50 \%$ between-group difference in mean VAS pain levels with a statistical power of $5 \%$ for type I error, viz. false positive results, and $20 \%$ for type II error, viz. false negative results.

The study participants were recruited among patients aged between 45 and 65 years with a clinical diagnosis of osteoarthritis (Research Diagnostic Criteria for Temporomandibular Disorders (RDC/TMD) version 1.0 - axis I group IIIb) (22) and with unilateral joint pain lasting from more than 6 months. All patients should have magnetic resonance (MR) signs of TMJ degeneration, as shown by a deformation due to subchondral cyst, surface erosion, osteophyte or generalised sclerosis $(23,24)$ (Fig. 1). Based on recent findings showing the influence of psychosocial factors on treatment effectiveness (18), patients with RDC/ TMD axis II high levels of pain-related impairment (i.e. Graded Chronic Pain Scale grade III or IV) were excluded from the study. Patients were recruited consecutively until reaching the targeted size of 30 subjects and they were randomly assigned to one of the three groups receiving the following treatment protocols: single-session TMJ lavage plus viscosupplementation with high-molecular weight (i.e. $7000 \mathrm{kDa}$ ) hyaluronic acid (Durolane $\mathrm{SJ}^{\circledR *}$ ) (Group A), singlesession TMJ lavage plus viscosupplementation with medium-molecular weight (i.e. $1200 \mathrm{kDa}$ ) hyaluronic acid (Sinovial ${ }^{\circledR \dagger}$ ) (Group B), five weekly TMJ lavages plus viscosupplementation with the same mediummolecular weight HA than group B (Group C). Randomization of patients between groups was achieved according to a [A-B-C-C-B-A] sequence for inclusion in the different groups. All groups of patients were followed up with multiple observation points at the end of treatment ( 1 week after the intervention), at 3 months and at 6 months. Patients were instructed to have a 2 -week washout period before starting the treatment protocol and to not use medications on

*Bioventus, Durham, NC, USA.

†IBSA Farmaceutici, Lodi, Italy. 


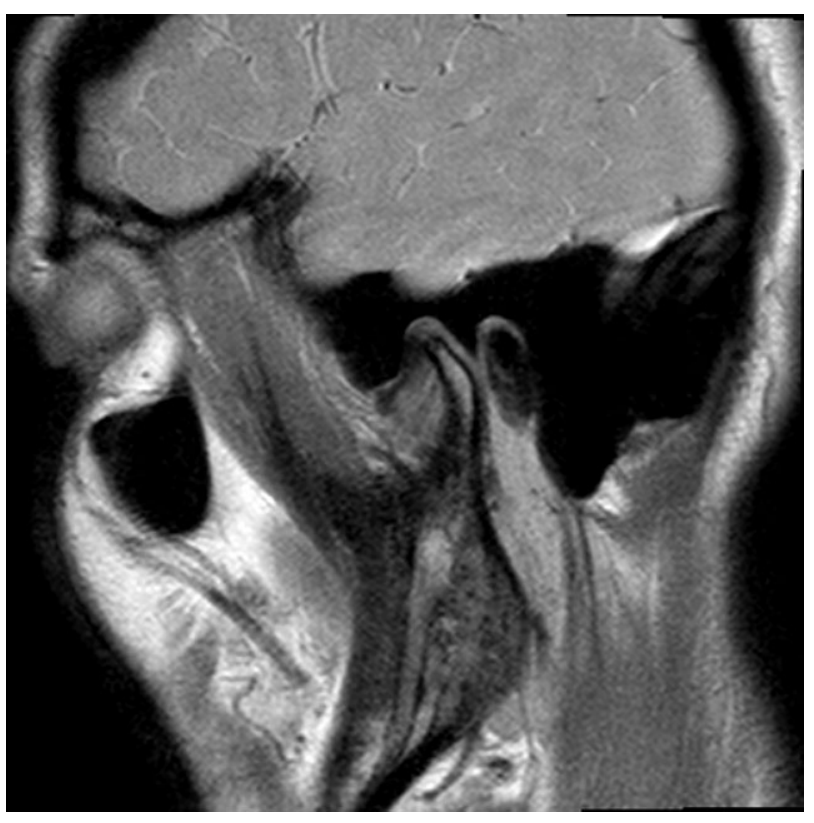

Fig. 1. Temporomandibular joint (TMJ) structural changes typical of osteoarthrosis (i.e. condylar cortical flattening and erosion) in a joint with an anteriorly displaced disc.

routine basis during the active treatment and followup periods (i.e. only paracetamol $1000 \mathrm{mg}$ was allowed in the immediate post-intervention phases).

All interventions were performed by one of the two leading investigators (L.G.-N., D.M.) according to the single-needle arthrocentesis technique described by Guarda-Nardini et al. (25), which adopted only one needle for both saline fluid injection and ejection. The technique was performed under local anaesthesia and, on average, an amount of about $10 \mathrm{~mL}$ saline was used for joint lavage. After joint lavage, patients received $1 \mathrm{~mL}$ hyaluronic acid.

For each patient, along with the primary outcome variable, a number of secondary outcome parameters were assessed: subjective chewing efficiency (0-10 VAS scale with 0 being the worst efficiency ever and 10 the best efficiency ever); functional limitation on a five-point scale with 0 being the lowest and 4 the maximum values; perceived subjective treatment effectiveness on a five-point scale with 0 being no perceived effectiveness and 4 being the maximum effectiveness; jaw range of motion function in millimetres. All the outcome variables were evaluated at baseline, at each intervention appointment (for patients of group $\mathrm{C}$ ), at the end of treatment, and at the 3-month and 6-month follow-up. The subjective variables (i.e. pain levels, chewing efficiency, functional limitation) were assessed as the average values during the time span occurring since the last observation point, with the exception of baseline values, which referred to the average values over the last month. All the outcome parameters were recorded by the same physician (A.R.) fully blinded to the group to which the patients belonged.

In the attempt to minimise bias related with patients' knowledge of the joint status, the patients received only basic advices about their need to undergo TMJ viscosupplementation, without any further specifications on the potential different benefit of administering joint lavage plus HA injections according to the different protocol strategies. All patients gave their written consensus to the intervention, and the study achieved official approval by the University Review Board and Medical Direction. None of the authors have any kind of conflict of interests or received financial support for the present investigation.

For statistical purposes, a nonparametric test was performed to assess the existence of significantly different between-group treatment effects at the three observation points. In the case that significances were detected, comparisons were performed between the different pairs of protocols to identify the precise collocation of the significance (A vs. B; A vs. C; B vs. C). For all comparisons, statistical significance was set at $P<0.05$.

\section{Results}

Thirty patients (ten per group) entered the study protocol. All of them completed the study, which was not undermined by any dropouts (Fig. 2). The groups were not significantly different as for demographic features, with mean age values ranging from $56.8 \pm 2.7$ to $60 \cdot 1 \pm 4.5$ years, and at least nine female subjects per group. No side effects were observed in any patients. At baseline, values of the three treatment groups were not significantly different in any outcome variables. At the end of treatment (first week after the intervention) and the follow-up observation points, improvement with respect to mean baseline values was recorded in all three treatment groups.

Group A patients, receiving a single TMJ lavage plus high-molecular weight hyaluronic acid, showed a mean decrease in VAS pain levels of 0.7 points at 


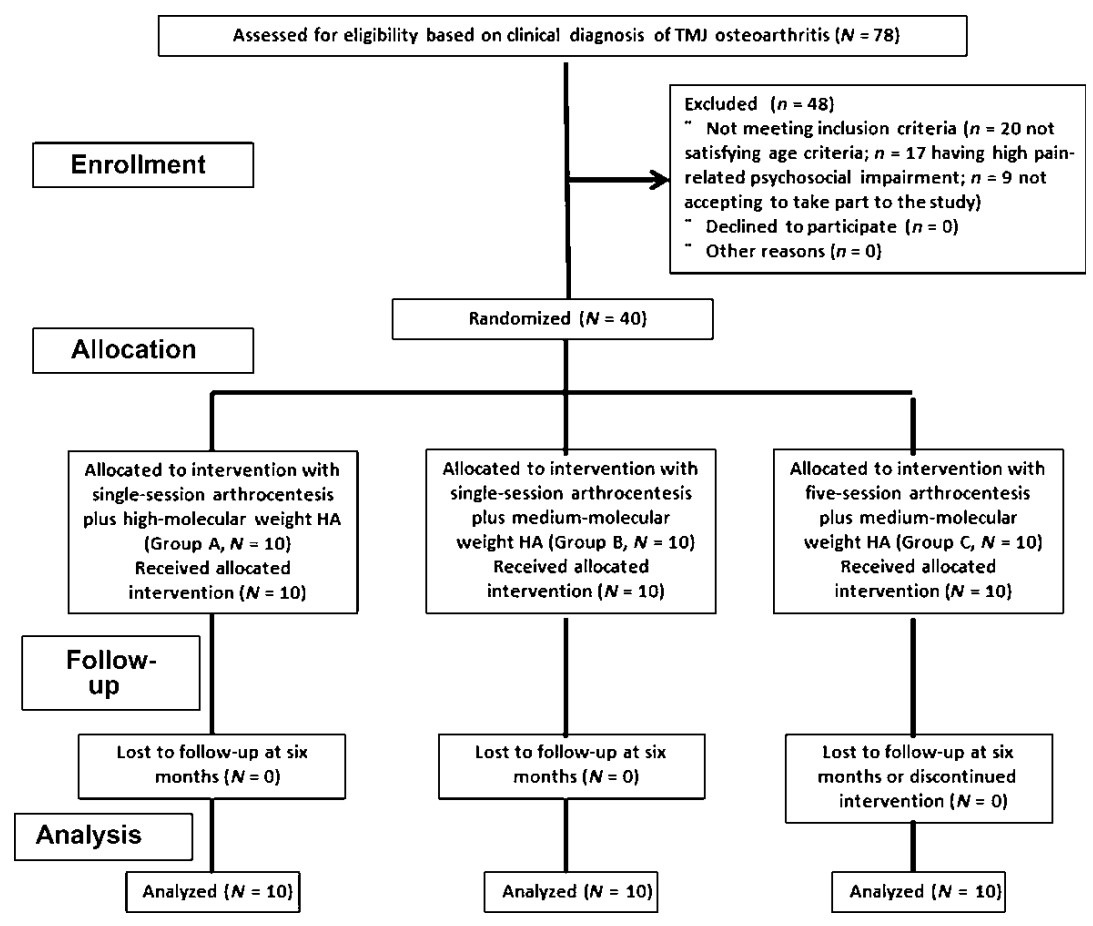

Fig. 2. CONSORT flow diagram.

1 week, with a progressive improvement up to 1.9 points lower than baseline at 6 months. At the 6month follow-up, $70 \%$ of patients were still referring decreased pain levels with respect to baseline. All the data referring to the other outcome variables were shown in Table 1.

Group B patients, receiving a single TMJ lavage plus molecular weight hyaluronic acid, showed a $2 \cdot 1$ VAS points decrease in pain levels at the 1-week follow-up, and less improvement at the successive observation points. At 6 months, $60 \%$ of patients were still referring decreased pain levels with respect to baseline. All the data referring to the other outcome variables were shown in Table 2 .
Group C patients, receiving five weekly TMJ lavages plus medium-molecular weight hyaluronic acid, showed an end-of-treatment decrease in VAS pain levels of 2.8 points, with further improvement to up to $4 \cdot 1$ points at 6 months. At 6 months, $100 \%$ of patients were referring decreased pain levels with respect to baseline. All the data referring to the other outcome variables were shown in Table 3.

Nonparametric permutation analyses showed that the global effect of treatment was significantly different between the three protocols $(P=0 \cdot 024)$. Thus, pairwise comparisons were made to identify the significant differences between each pair of protocols at the three observation points.

Table 1. Group A. Changes over time in the outcome variables

\begin{tabular}{|c|c|c|c|c|c|}
\hline Outcome variables & $\begin{array}{l}\text { Expected sign for } \\
\text { improvement } \\
(+ \text { or }-)\end{array}$ & Baseline & $\begin{array}{l}\text { Difference } \\
\text { at } 1 \text { week }\end{array}$ & $\begin{array}{l}\text { Difference } \\
\text { at } 3 \text { months }\end{array}$ & $\begin{array}{l}\text { Difference } \\
\text { at } 6 \text { months }\end{array}$ \\
\hline Chewing efficiency $(0-10)$ & + & $6 \cdot 2$ & $+0 \cdot 4$ & $+1 \cdot 3$ & $+1 \cdot 4$ \\
\hline Pain levels $(0-10)$ & - & $6 \cdot 4$ & $-0 \cdot 7$ & $-2 \cdot 3$ & $-1 \cdot 9$ \\
\hline Functional limitation (0-4) & - & $1 \cdot 8$ & $-0 \cdot 3$ & $-0 \cdot 9$ & $-1 \cdot 3$ \\
\hline Perceived efficacy $(0-4)$ & + & $1 \cdot 7$ & n.a* & $+0 \cdot 9$ & $+1 \cdot 0$ \\
\hline Mouth opening (mm) & + & $37 \cdot 5$ & $-0 \cdot 4$ & $+1 \cdot 2$ & $+3 \cdot 4$ \\
\hline
\end{tabular}

*Baseline values of perceived efficacy actually refer to the end-of-treatment (1 week) observation point. 
Table 2. Group B. Changes over time in the outcome variables

\begin{tabular}{llcccc}
\hline Outcome variables & $\begin{array}{l}\text { Expected sign for } \\
\text { improvement }(+ \text { or }- \text { ) }\end{array}$ & Baseline & $\begin{array}{l}\text { Difference } \\
\text { at l week }\end{array}$ & $\begin{array}{l}\text { Difference at } \\
\text { three months }\end{array}$ & $\begin{array}{l}\text { Difference } \\
\text { at } 6 \text { months }\end{array}$ \\
\hline Chewing efficiency (0-10) & + & $6 \cdot 1$ & $+1 \cdot 3$ & $+1 \cdot 2$ & $+1 \cdot 1$ \\
Pain levels (0-10) & - & $6 \cdot 2$ & $-2 \cdot 1$ & $-1 \cdot 3$ & $-1 \cdot 4$ \\
Functional limitation (0-4) & - & $2 \cdot 3$ & $-1 \cdot 1$ & $-0 \cdot 9$ & $-1 \cdot 3$ \\
Perceived efficacy (0-4) & + & $2 \cdot 2$ & n.a* & $+0 \cdot 6$ & $+3 \cdot 1$ \\
Mouth opening (mm) & + & $36 \cdot 0$ & $+3 \cdot 0$ & $+3 \cdot 3$ & +3 \\
\hline
\end{tabular}

*Baseline values of perceived efficacy actually refer to the end-of-treatment (1 week) observation point.

Table 3. Group C. Changes over time in the outcome variables

\begin{tabular}{llcccc}
\hline Outcome variables & $\begin{array}{l}\text { Expected sign for } \\
\text { improvement (+ or }- \text { ) }\end{array}$ & Baseline & $\begin{array}{l}\text { Difference } \\
\text { at 1 week }\end{array}$ & $\begin{array}{l}\text { Difference } \\
\text { at 3 months }\end{array}$ & $\begin{array}{l}\text { Difference } \\
\text { at } 6 \text { months }\end{array}$ \\
\hline Chewing efficiency (0-10) & + & $6 \cdot 6$ & $+1 \cdot 2$ & $+1 \cdot 4$ & $+1 \cdot 9$ \\
Pain levels (0-10) & - & $6 \cdot 1$ & $-2 \cdot 8$ & $-3 \cdot 0$ & $-4 \cdot 1$ \\
Functional limitation (0-4) & - & $2 \cdot 2$ & $-0 \cdot 5$ & $-0 \cdot 3$ & $-1 \cdot 1$ \\
Perceived efficacy (0-4) & + & $2 \cdot 8$ & n.a & $-0 \cdot 1$ & $+0 \cdot 6$ \\
Mouth opening (mm) & + & $39 \cdot 4$ & $+2 \cdot 1$ & $+2 \cdot 5$ & $+4 \cdot 4$ \\
\hline
\end{tabular}

*Baseline values of perceived efficacy actually refer to the end-of-treatment ( 1 week) observation point.

The single-session treatments did not show any significantly different effect in any outcome variables at any observation points. The global $P$-value for the difference of treatment effect was 0.93 , thus suggesting that, if existing, differences in treatment-related effects were negligible. On the contrary, the five-session protocol was significantly superior to both singlesession protocols, with global $P$-values of 0.012 with respect to protocol $\mathrm{A}$ and 0.003 with respect to protocol B. The combined $P$-values for differences in treatment effects were significant versus both singlesession protocols at the end-of-treatment assessment ( $P=0.005$ and $P=0.007$, respectively), remained significant at the 3-month follow-up only versus the single-session protocol with medium-molecular weight HA $(P=0.003)$, whilst they were not significant at 6 months $(P=0.11$ and 0.07 , respectively). As for findings of specific outcome variables, improvement in pain levels was significantly superior to the singlesession interventions at all three observation points, with $P$-values ranging from 0.004 to 0.036 when treatment effects were compared to group $\mathrm{A}$ and from 0.003 to 0.038 when compared to group B. Interestingly, with minor exceptions, no significant differences were shown as far as the functional limitation, the perceived treatment efficacy and the mouth opening values (Table 4).

\section{Discussion}

The literature on TMJ viscosupplementation has been providing increasing evidence on the potential effectiveness of such strategy to manage degenerative disorders. Clinical researches on the argument covered various topics, ranging from case series with mediumto long-term follow-up to randomized controlled trials comparing the effectiveness of different drugs and interventions $(10,12,15)$. From those studies, the need for identifying the ideal protocol in terms of cost-to-benefit ratio emerged. In particular, less invasive strategies with respect to the standard of reference five-session protocol, which was proven as the most effective in the short-term period, should be investigated.

In the present study, three treatment protocols were compared. The effectiveness of a cycle of five weekly joint lavages plus hyaluronic acid injections in the management of TMJ degenerative disorders was adopted as a reference, and it was compared with the outcomes of two single-session protocols of lavage and viscosupplementation, one providing mediumand one providing high-molecular weight HA. The rationale for the study was to assess the potential effectiveness of the least invasive strategy as possible, viz. a single-session intervention, with respect to the 
Table 4. Permutation test. Pairwise between-group comparisons

\begin{tabular}{|c|c|c|c|c|c|c|c|}
\hline Comparison & Follow-up & $\begin{array}{l}\text { Chewing } \\
\text { efficiency }\end{array}$ & Pain levels & $\begin{array}{l}\text { Functional } \\
\text { limitation }\end{array}$ & $\begin{array}{l}\text { Perceived } \\
\text { efficacy }\end{array}$ & $\begin{array}{l}\text { Mouth } \\
\text { opening }\end{array}$ & $\begin{array}{l}\text { Combined } \\
P \text {-value }\end{array}$ \\
\hline \multirow[t]{3}{*}{ Group A vs. B } & At 1 week & $0 \cdot 899$ & $0 \cdot 269$ & $0 \cdot 317$ & $1 \cdot 000$ & 0.535 & $0 \cdot 60$ \\
\hline & At 3 months & $0 \cdot 177$ & 0.575 & 0.785 & $0 \cdot 991$ & 0.636 & $0 \cdot 74$ \\
\hline & At 6 months & $0 \cdot 546$ & 0.641 & $1 \cdot 000$ & 0.676 & 0.879 & 0.94 \\
\hline \multirow[t]{3}{*}{ Group A vs. C } & At 1 week & 0.057 & $0.004^{* *}$ & $0.012 *$ & $0 \cdot 145$ & $0 \cdot 256$ & $0.005^{* *}$ \\
\hline & At 3 months & $0 \cdot 382$ & $0.036^{*}$ & 0.646 & $0 \cdot 165$ & 0.610 & $0 \cdot 103$ \\
\hline & At 6 months & $0 \cdot 102$ & $0.012^{*}$ & $0 \cdot 266$ & 0.531 & 0.527 & $0 \cdot 11$ \\
\hline \multirow[t]{3}{*}{ Group B vs. C } & At 1 week & $0.025^{*}$ & $0.017^{*}$ & $0 \cdot 108$ & $0.020^{*}$ & 0.332 & $0.007^{* *}$ \\
\hline & At 3 months & $0.018^{*}$ & $0.003^{* *}$ & $0 \cdot 190$ & $0 \cdot 162$ & $0 \cdot 134$ & $0.003^{* *}$ \\
\hline & At 6 months & $0.029^{*}$ & $0.038^{*}$ & $0 \cdot 278$ & $0 \cdot 417$ & $0 \cdot 214$ & 0.07 \\
\hline
\end{tabular}

Significance levels for all outcome variables at the three observation points. ${ }^{*} P<0.05 ; *^{*} P<0.01$.

standard of reference. The single-session intervention was performed with two different HA to assess for potential differences related with the use of a drug that was commonly administered in a single intervention (i.e. high-molecular weight HA [protocol A]) or the same drug that was used for the multiple-session protocol (i.e. medium-molecular weight HA [protocol B]).

The findings at 6 months supported the effectiveness of all treatment protocols, possibly suggesting that symptom fluctuation over time and other factors not strictly related with the specificity of intervention may partly explain patients' improvement $(26,27)$. Future researches featuring an additional control group of matched untreated patients or subjects undergoing joint lavage alone are needed to get deeper into this issue. In any case, as a major point of strength of this study's design, it should be remarked that patients were matched as far as their psychosocial profile was concerned, based on recent suggestions that axis II profiles are important predictors of treatment effectiveness (18). The rationale behind this choice, which appears in contrast with the recent IMMPACT recommendations on the outcome measures for clinical trials on chronic pain (28), is that the inclusion of patients with different levels of painrelated disability might have influenced the results and put the focus of this comparative trial on the patient's related psychosocial factors. The focus of this investigation was instead on the comparison of different treatment protocols, with a look at the cost-tobenefit ratio associated with a possible reduction in the number of serial interventions. Once again, future researches on individuals with severe psychosocial impairment may help clarifying the complex painpsyche relationship at the treatment level.

Within these premises, the reference protocol (i.e. five weekly TMJ lavages plus medium-molecular weight HA [protocol C]) was significantly superior to both single-session interventions, with $100 \%$ of patients still referring decreased pain levels at the end of the follow-up period. On the other hand, the two single-session protocols did not show any significant differences at any observation points. In spite of this global picture that supports the hypothesis of a superiority of the multiple-session protocol, it must be pointed out that its significantly different effectiveness was mainly due to the decreased pain levels, whilst improvement in self-perceived functional limitation and perceived treatment efficacy was not different between the three protocols.

Taken together, results are thus open to an encouraging interpretation as far as the possibility to reduce the number of serial appointments for viscosupplementation is concerned. Indeed, the hypothesis that the five-session protocol is not an optimal strategy to manage symptoms of TMJ degenerative disorders from a cost-to-benefit ratio cannot be disregarded. On this purpose, it should be interesting to assess the effectiveness of three-session protocols, which showed promising outcomes for the management of knee osteoarthritis and allowed reducing the number of interventions, with obvious advantages from a biological and financial viewpoint (29). At present, there are no studies on the effectiveness of such protocol for TMJ disorders, and studies on the argument are recommended. In addition, possible imaging-detected changes on the articular structures induced by the 
various viscosupplementation protocols are to be investigated.

\section{Conclusions}

The present investigation aimed to compare the effectiveness of two single-session protocols, either adopting medium- or high-molecular weight hyaluronic acid, with the reference five-session protocol of joint lavage plus viscosupplementation for the management of TMJ degenerative disorders. In a population of age-, sex-, and psychosocial aspects-matched study groups, the standard of reference protocol proved to be superior at 6 months as far as the decrease in pain levels was concerned, whilst there were no differences between the two single-session interventions. The three protocols did not provide any different treatment effect as for some other secondary clinical outcome variables (e.g. perceived subjective efficacy, mouth opening) assessed in this investigation. Such finding suggests that there is further space for trials attempting to reduce the number of multiple interventions for TMJ viscosupplementation. The important clinical, biological and social implications of such a reduction should deserve attention in future researches.

\section{Acknowledgments}

The authors declare they do not have any conflict of interest and did not receive any funding for this investigation.

\section{References}

1. Manfredini D, Ahlberg J, Winocur E, Guarda-Nardini L, Lobbezoo F. Correlation of RDC/TMD axis I diagnoses and axis II pain-related disability. A multicenter study. Clin Oral Investig. 2011;15:749-756.

2. de Souza RF, Lovato da Silva CH, Nasser M, Fedorowicz Z, Al-Muharraqi MA. Interventions for the management of temporomandibular joint osteoarthritis. Cochrane Database Syst Rev. 2012;4:CD007261.

3. Manfredini D, Piccotti F, Guarda-Nardini L. Hyaluronic acid in the treatment of TMJ disorders. A systematic review of the literature. Cranio. 2010;28:166-176.

4. Nitzan DW, Dolwick MF, Martinez GA. Temporomandibular joint arthrocentesis: a simplified method for severe, limited mouth opening. J Oral Maxillofac Surg. 1991;49:1163-1167.

5. Guarda-Nardini L, Ferronato G. TMJ arthrocentesis. In: Manfredini D, ed. Current concepts on temporomandibular disorders. Berlin: Quintessence Publishing; 2010:393-402.
6. Altman RD. Intra-articular sodium hyaluronate in osteoarthritis of the knee. Semin Arthritis Rheum. 2000;30:11-18.

7. Ehrlich GE. Osteoarthritis. In: Rakel BE, Bope ET, eds. Conn's current therapy, 58th edn. New York: Elsevier; 2006:921.

8. Nitzan DW. "Friction and adhesive forces": possible underlying causes for temporomandibular joint internal derangement. Cells Tissues Organs. 2003;174:6-16.

9. Guarda-Nardini L, Tito R, Staffieri A, Beltrame A. Treatment of patients with arthrosis of the temporomandibular joint by infiltration of sodium hyaluronate: a preliminary study. Eur Arch Otorhinolaryngol. 2002;259:279-284.

10. Guarda-Nardini L, Stifano M, Brombin C, Salmaso L, Manfredini D. A one-year case series of arthrocentesis with hyaluronic acid injections for temporomandibular joint osteoarthritis. Oral Surg Oral Med Oral Pathol Oral Radiol Endod. 2007;103:e14-e22.

11. Manfredini D, Bonnini S, Arboretti R, Guarda-Nardini L. Temporomandibular joint osteoarthritis: an open label trial of 76 patients treated with arthrocentesis plus hyaluronic acid injections. Int J Oral Maxillofac Surg. 2009;38:827834.

12. Møystad A, Mork-Knutsen BB, Bjørnland T. Injection of sodium hyaluronate compared to a corticosteroid in the treatment of patients with temporomandibular joint osteoarthritis: a CT evaluation. Oral Surg Oral Med Oral Pathol Oral Radiol Endod. 2008;105:e53-e60.

13. Oliveras-Moreno JM, Hernandez-Pacheco E, Oliveras-Quintana T, Infante-Cossio P, Gutierrez-Perez JL. Efficacy and safety of sodium hyaluronate in the treatment of Wilkes stage II disease. J Oral Maxillofac Surg. 2008;66:2243-2246.

14. Guarda-Nardini L, Ferronato G, Favero L, Manfredini D. Predictive factors of hyaluronic acid injections short-term effectiveness for TMJ degenerative joint disease. J Oral Rehabil. 2011;38:315-320.

15. Manfredini D, Rancitelli D, Ferronato G, Guarda-Nardini L. Arthrocentesis with or without additional drugs in temporomandibular joint inflammatory-degenerative disease: comparison of six treatment protocols*. J Oral Rehabil. 2012;39:245-251.

16. Guarda-Nardini L, Ferronato G, Manfredini D. Two-needle vs. single-needle technique for TMJ arthrocentesis plus hyaluronic acid injections: a comparative trial over a sixmonth follow up. Int J Oral Maxillofac Surg. 2012;41:506513.

17. Guarda-Nardini L, Cadorin C, Frizziero A, Ferronato G, Manfredini D. Comparison of 2 hyaluronic acid drugs for the treatment of temporomandibular joint osteoarthritis. J Oral Maxillofac Surg. 2012;70:2522-2530.

18. Manfredini D, Favero L, Del Giudice A, Masiero S, Stellini E, Guarda-Nardini L. Axis II psychosocial findings predict effectiveness of TMJ hyaluronic acid injections. Int J Oral Maxillofac Surg. 2013;42:364-368.

19. Guarda-Nardini L, Rossi A, Ramonda R, Punzi L, Ferronato G, Manfredini D. Treatment effectiveness of viscosupplementation in temporomandibular joints with and without effusion. Int J Oral Maxillofac Surg. 2014;43:1218-1223. 
20. Jensen MP, Chen C, Brugger AM. Interpretation of visual analog scale ratings and change scores: a reanalysis of two clinical trials. J Pain. 2003;4:407-414.

21. Manfredini D, Tognini F, Biondi K, Bosco M. Sample size calculation for studies on temporomandibular disorders. Minerva Stomatol. 2003;52:309-319.

22. Dworkin S, LeResche L. Research diagnostic criteria for temporomandibular disorders: Review, criteria examinations and specifications, critique. J Craniomandib Disord Fac Oral Pain. 1992;6:301-355.

23. Ahmad M, Hollender L, Anderson Q, Kartha K, Ohrbach R, Truelove EL et al. Research diagnostic criteria for temporomandibular disorders (RDC/TMD): development of image analysis criteria and examiner reliability for image analysis. Oral Surg Oral Med Oral Pathol Oral Radiol Endod. 2009; 107:844-860.

24. Manfredini D, Tognini F, Zampa V, Bosco M. Predictive value of clinical findings for temporomandibular joint effusion. Oral Surg Oral Med Oral Pathol Oral Radiol Endod. 2003;96:521-526.

25. Guarda-Nardini L, Manfredini D, Ferronato G. Arthrocentesis of the temporomandibular joint: a proposal for a singleneedle technique. Oral Surg Oral Med Oral Pathol Oral Radiol Endod. 2008;106:483-486.
26. Manfredini D, Favero L, Gregorini G, Cocilovo F, GuardaNardini L. Natural course of temporomandibular disorders with low pain-related impairment: a 2-to-3-year follow up study. J Oral Rehabil. 2013;40:436-442.

27. Greene CS, Goddard G, Macaluso GM, Mauro G. Topical review: placebo responses and therapeutic responses. How are they related? J Orofac Pain. 2009;23:93-107.

28. Dworkin RH, Turk DC, Farrar JT, Haythornthwaite JA, Jensen MP, Katz NP et al. IMMPACT. Core outcome measures for chronic pain clinical trials: IMMPACT recommendations. Pain. 2005; 1 13:9-19.

29. Pavelka K, Uebelhart D. Efficacy evaluation of highly purified intra-articular hyaluronic acid (Sinovial $\left({ }^{\circledR}\right)$ ) vs hylan GF20 (Synvisc $\left({ }^{\circledR}\right)$ ) in the treatment of symptomatic knee osteoarthritis. A double-blind, controlled, randomized, parallel-group non-inferiority study. Osteoarthritis Cartilage. 2011;19:1294-1300.

Correspondence: Daniele Manfredini, Viale XX Settembre 298, 54033 Marina di Carrara (MS) Italy.

E-mail: daniele.manfredini@tin.it 